\title{
O papel da casa Mario Taques Bittencourt na definição da obra de Vilanova Artigas
}

\author{
Marcio Cotrim \\ Arquiteto e Urbanista, doutor em Teoria e História da Arquitetura \\ pela Universitat Politècnica de Catalunya (2008), professor do \\ Departamento de Arquitetura e do PPGAU da Universidade Federal \\ da Paraíba, UFPB, pesquisador do Grupo de pesquisa Projeto \\ e Memória (LPPM-UFPB), Campus Universitário I, João Pessoa, \\ Paraíba, CEP 58051-900, 55 (83) 3216-7119, marciocotrim@ \\ gmail.com
}

\begin{abstract}
Resumo
Este artigo traça um paralelo entre os projetos elaborados por Vilanova Artigas e Carlos Cascaldi para a família Taques Bittencourt, destacando as diferenças entre o estudo inicial e o projeto definitivo da segunda casa, construída em 1959 e 1960. A comparação não busca desvelar o que levou Artigas e Cascaldi a alterarem de maneira drástica a direção projetual, mas perceber quais estratégias de projeto caracterizava esta movimentação. O argumento central é que entre um projeto e outro se situa com precisão os rumos tomados pela obra do arquiteto a partir dos anos 1960 delimitando, portanto, sua importância na formulação de uma corrente no quadro da arquitetura moderna brasileira.
\end{abstract}

Palavras-chave: Vilanova Artigas, casas, Mario Taques Bittencourt. mudança de rumo na arquitetura moderna brasileira durante a década de 1950 é, em seus termos gerais, aceita pela maioria dos críticos e pesquisadores do assunto. Alguns se centram nas rupturas com a produção imediatamente anterior, enquanto outros sublinham as eventuais continuidades. Simplificando todos os possíveis argumentos para um ou outro lado, em síntese, durante a década de 1950 o holofote, até então depositado sobre o caráter formalista da arquitetura moderna brasileira de matriz carioca, foi deslocado pelo interesse sobre os aspectos construtivos e em particular pela estrutura portante. Em última instância, acabou convertendo a técnica em linguagem. Também se aceita, com alguma ou outra variação, o papel central que Vilanova Artigas assumiu neste processo de mutação'.

Em setembro de 1970, um dos últimos números da revista Acrópole (n.377) foi dedicado na integra à obra de Vilanova Artigas, mais especificamente às escolas que tinha projetado na última década. Um pequeno texto na apresentação da edição, escrito pelo amigo e arquiteto Fabio Penteado, sugere que Artigas àquela altura não era apenas um importante e conhecido profissional, mas também um dos que mais tinha influenciado as gerações conseguintes à sua. O texto levava o título de "Vilanova Artigas, Construtor de Escolas"; Fabio Penteado atribuiu a Artigas o papel de "irmão mais velho, que faltando o pai larga de si e dá tudo o que tem, para formar os irmãos menores"2 . Embora o caráter metafórico da frase e possivelmente do título, dificulte uma compreensão mais objetiva, sugere um tortuoso caminho percorrido por Artigas durante sua vida profissional. O "pai" ausente pode ser interpretado como o Estado Novo do governo Vargas, ou ainda personificado por Lucio Costa. No entanto, mais adiante no texto, Fabio Penteado ampliou o sentido de "formar os irmãos menores", conferindo aos projetos de Artigas o caráter de modelos: "Por isso Artigas tem projetos no Brasil inteiro. É o arquiteto que mais tem projetos" ${ }^{3}$. Nestes mesmos anos, Yves Bruand ao escrever sua tese - que veio a ser publicada apenas em 1981 - outorgou a Artigas o papel de chef de file. 
4 GUERRA, Abilio; CASTROVIEJO RIBEIRO, Alessandro José. Casas brasileiras do século XX. Arquitextos, São Paulo, n. 07.074.01, Vitruvius, jul. 2006, <vitruvius. com.br/revistas/read/arquitextos/07.074/335>

5 GUERRA, Abilio: CASTROVIEJO RIBEIRO, Alessandro José. Casas brasileiras do século XX. Arquitextos, São Paulo, n. 07.074.01, Vitruvius, jul. 2006, <vitruvius. com.br/revistas/read/arquitextos/07.074/335>.

Figura 1: Casa Mario Taques Bittencourt em construção. Arq. Vilanova Artigas e Carlos Cascaldi, 1959, São Paulo. Fonte: Arquivo FAU/USP.
Praticamente vinte anos depois, Guerra e Castroviejo, em meados dos anos 2000, aprumaram tal interpretação em termos estritamente arquitetônicos, indicando o papel fundamental da segunda casa construída para a família Taques Bittencourt (1959) (figura 1) na formulação de uma corrente no quadro da arquitetura moderna brasileira:

Dela questões estéticas e problemas construtivos que informaram um fazer arquitetônico por anos a fio, desdobrando-se em outros projetos e tipologias. ${ }^{4}$

Neste caso a discussão foi canalizada para questões projetuais, em particular as estruturais, na medida em que apontaram para a alteração da "solução tradicional laje, viga e pilar":

É notável a solução estrutural das paredes de carga sobre poucos e leves apoios conformando pórticos geralmente dispostos na borda das volumetrias, de maneira a alterar em parte a solução tradicional do sistema laje, viga e pilar. ${ }^{5}$
Ao contrário do exoesqueleto criado pela repetição dos pórticos do MAM, da Escola Brasil-Paraguay ou da Fábrica Duchen (figura 02), a conformação de dois pórticos periféricos nos limites laterais da segunda casa Taques Bittencourt definiu uma potente solução genérica, a delimitação do espaço através de uma única cobertura e da projeção da sombra resultante. Ao longo dos anos 1960 a cobertura única, como estratégia projetual, aclimatou-se a diferentes programas e foi incessantemente explorada na definição da imagem final de muitos projetos a partir de então. Boa parte de seu interesse se deu pela possibilidade de conexão que gerou com a cidade através das distintas formas de ocupação das parcelas e, sobretudo, por ser parte imprescindível de uma estratégia de organização do programa em níveis intermediários.

A estratégia estrutural testada na casa Mario Taques Bittencourt e a solução genérica que preconizou foi decisiva na formulação de uma corrente no quadro da arquitetura moderna brasileira que desfrutou de certo protagonismo a partir dos anos 1960.

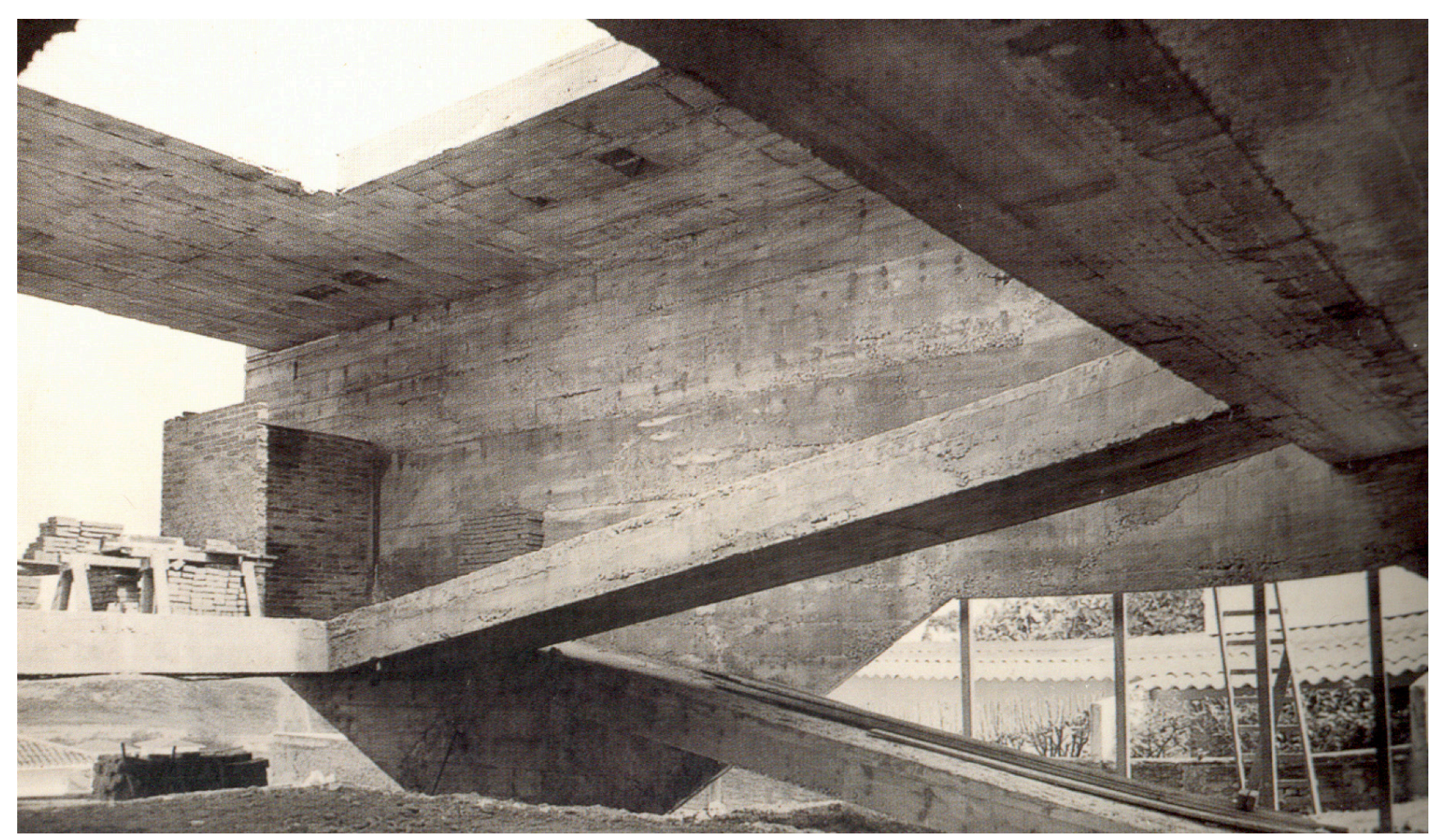



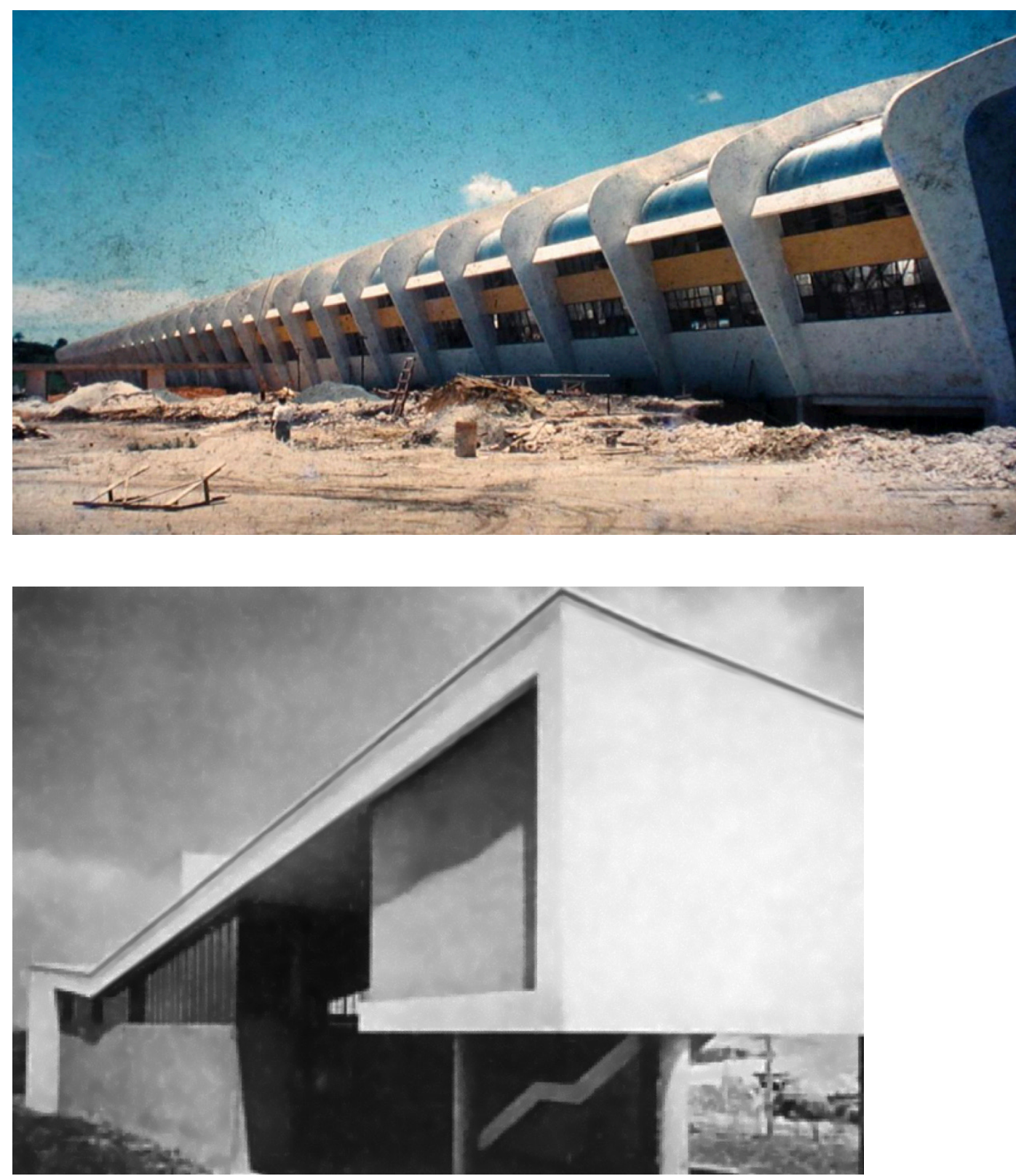

Figura 2 (topo): Fábrica Duchen, Arq. Oscar Niemeyer, 1949-1951, São Paulo/Guarulhos. Fonte: <sãopauloantiga.com.br>.

Figura 3: Primeira casa construída para a família Taques Bittencourt (1948) na Rua Votuporanga no bairro do Sumaré em São Paulo. Arq. Vilanova Artigas e Carlos Cascaldi. Fonte: Arquivo FAU/USP. 


\section{A segunda casa da família Taques Bittencourt}

José Mario Taques Bittencourt era médico, militante do partido comunista e amigo pessoal de Artigas desde 1945. O arquiteto projetou três casas para a família na mesma rua do bairro do Sumaré na cidade de São Paulo. A primeira, construída em 1948 (figura 3), foi eclipsada na historiografia da arquitetura possivelmente pela semelhança com outra casa do arquiteto, no bairro do Campo Belo, construída para ele próprio no mesmo período. A terceira (figura 5), construída em 1981 - o último projeto residencial de Artigas a ser construído -, foi projetada para a filha do casal Bittencourt. A segunda, construída em 1959, é sem sombra de dúvida, a mais famosa e uma das mais importantes casas projetadas pelo arquiteto como foi destacado anteriormente.

Figura 4: Vista aérea das três casas construída para a família Taques Bittencourt na Rua Votuporanga no bairro do Sumaré em São Paulo. Arq. Vilanova Artigas e Carlos Cascaldi. Fonte: Google Earth.
A primeira (1948) se alinha à arquitetura moderna de matriz carioca, é definida por volumes trapezoidais destacados por meio de vigas perimetrais e articulados de modo a formarem uma cobertura tipo "asa de borboleta". Sua planta é retangular e alongada e se organiza em torno da cozinha e do banheiro.
A terceira (1981) mantém importantes aspectos em comum com a segunda (1959), construída 22 anos antes: compartilham um tipo de planta muito parecido, a mesma premissa volumétrica e estrutural, têm praticamente o mesmo programa e se relacionam de forma semelhante com o lote. Juntas poderiam servir como um exemplo potente da relação proposta entre as casas e a malha urbana. Entretanto, revelam como um mesmo modo de pensar o projeto arquitetônico, condicionado sob uma nova realidade urbana, perde parte significativa dos elementos vitais que o constituíram. Em 1981, a justaposição entre o espaço público e o doméstico foi evidentemente restringida pela necessidade de segurança (muros, câmeras e grades) frente à nova realidade urbana da cidade de São Paulo quando comparada a 1959.

A casa de 1959 - a segunda construída para a família - ao contrário, foi marcada não apenas pela materialização de um otimismo com relação à cidade de São Paulo, mas, sobretudo com o país. O desenvolvimento em curso de uma sofisticada cultura técnica indicava o bom rumo que o país tinha tomado. A casa pode ser vista como parte de uma experimentação, ao mesmo tempo, tipológica,

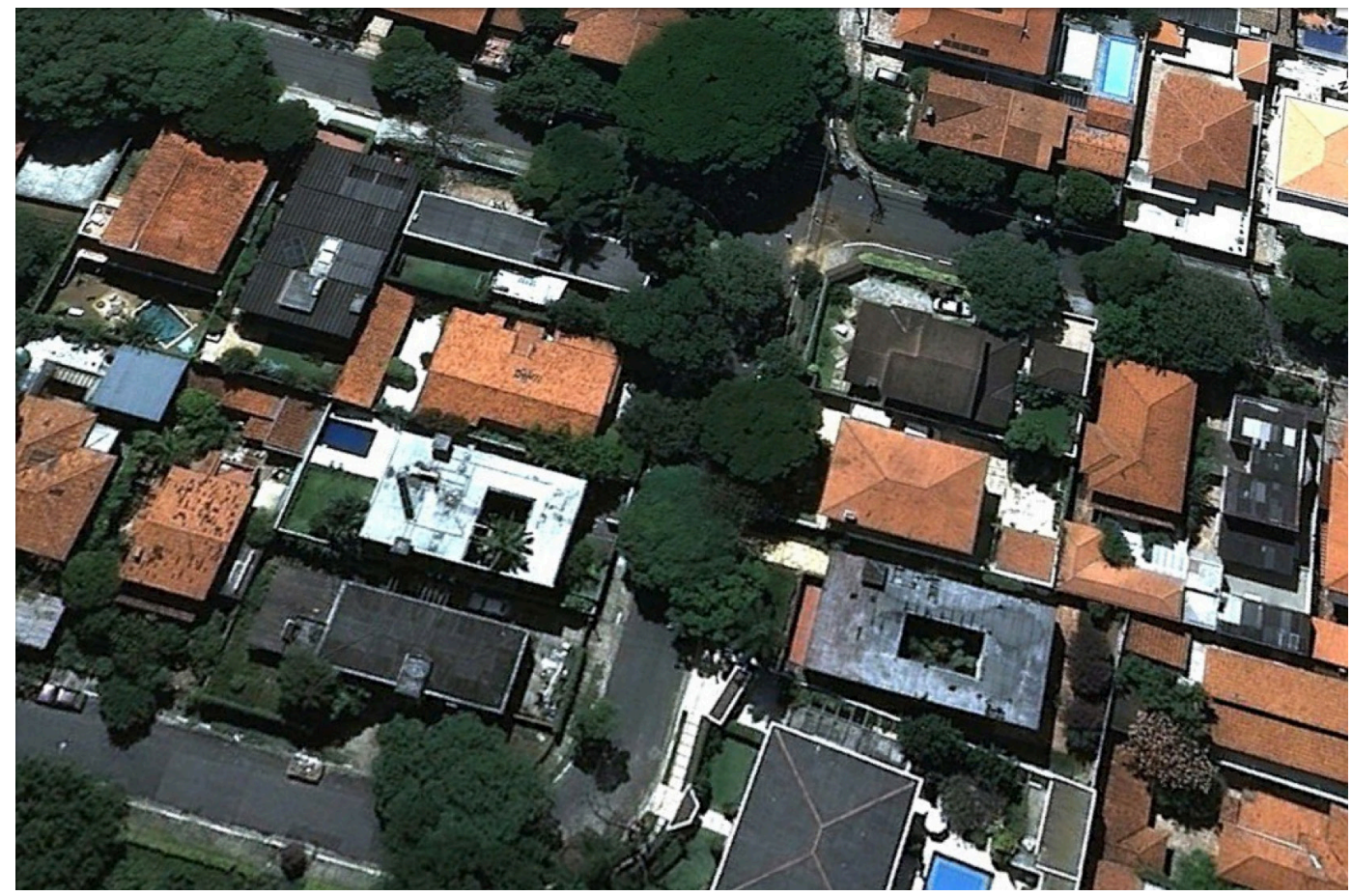



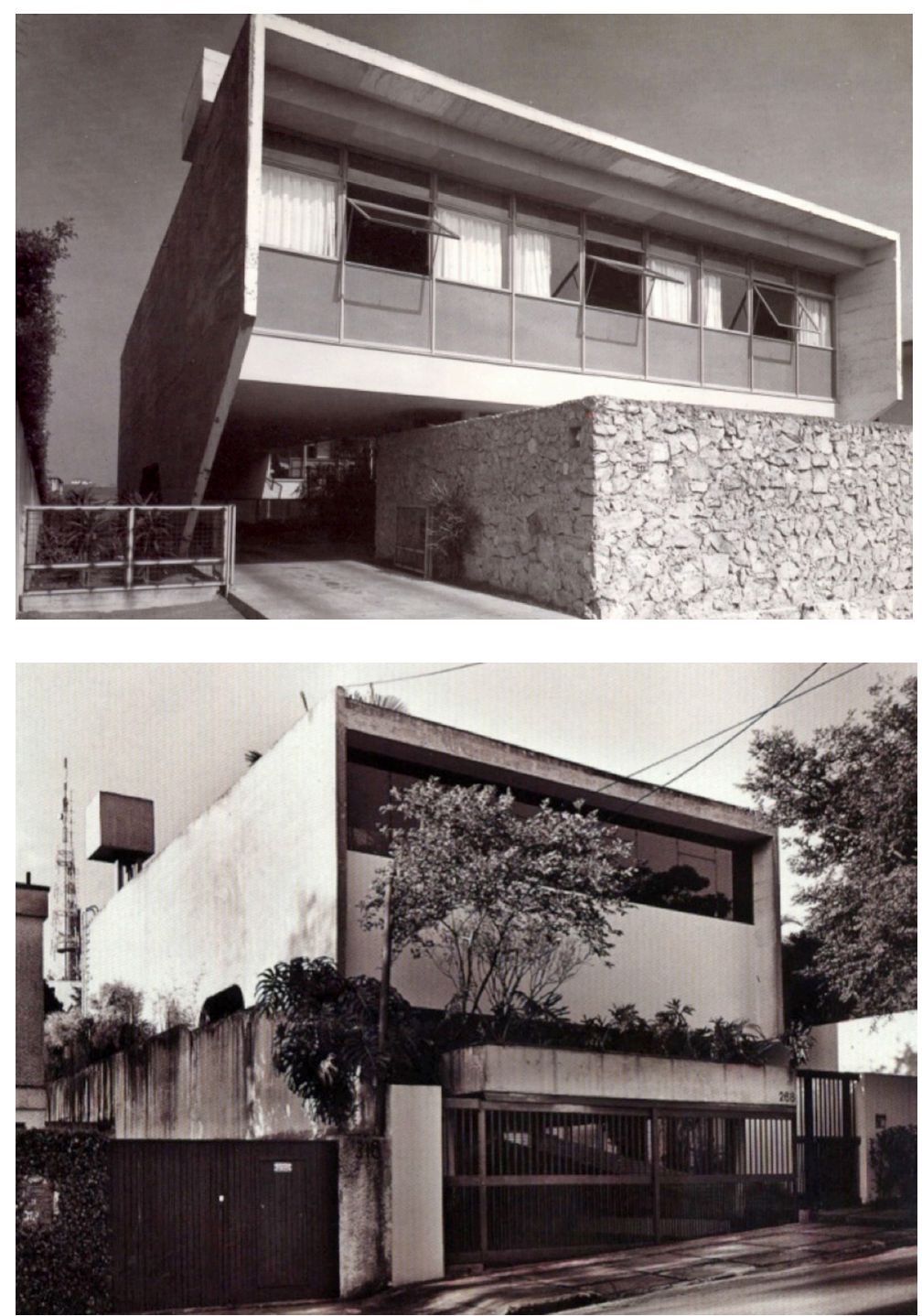

Figura 5: A segunda (1959) e a terceira (1981) casa construídas para a família do médico Mario Taques Bittencourt na Rua Votuporanga em São Paulo. Arq. Vilanova Artigas e Carlos Cascaldi. Fonte: Arquivo FAU/USP. estrutural e social, e no discurso que enaltecia a técnica como forma de expressão pode-se encontrar os argumentos necessários para justificá-la. Um entrelaçamento que alicerçou a atração exercida pela obra e possibilitou a delimitação dos pressupostos contidos na base do que chegou a conhecer-se como uma escola, assumindo e transformando o caráter representativo da arquitetura a que pretendia dar continuidade. A tentativa de renovação dos valores intrínsecos da experiência moderna pretendeu garantila como produção cultural, autônoma e emancipada, que se supunha capaz de contribuir no processo de emancipação política e econômica brasileira.

A redução dos componentes de sua estrutura foi decisiva, resumindo-os a duas empenas de $21,50 \mathrm{~m}$ posicionadas de maneira perpendicular à rua. 0 conjunto, como já foi dito, forma dois pórticos nos quais se fundem todas as vigas e os quatro únicos pontos de apoios da estrutura. As duas empenas são unidas por lajes nervuradas (unidirecionais) interligadas por rampas articuladas em níveis intermediários. As rampas assumem, além das funções de circulação vertical e horizontal, função estrutural. Fora esses elementos - todos estruturais - foram utilizados apenas fechamentos e divisórias de madeira, vidro ou alvenaria convencional, com exceção de dois muros em concreto ciclópico. Ainda assim, ao utilizá-los, Artigas marcou sua independência da estrutura principal através de outros materiais, como vidros ou grelhas para circulação de ar nos dormitórios. A imagem final alcançada pelo edifício releva de forma definitiva a intenção de determiná-lo por seus elementos estruturais. 

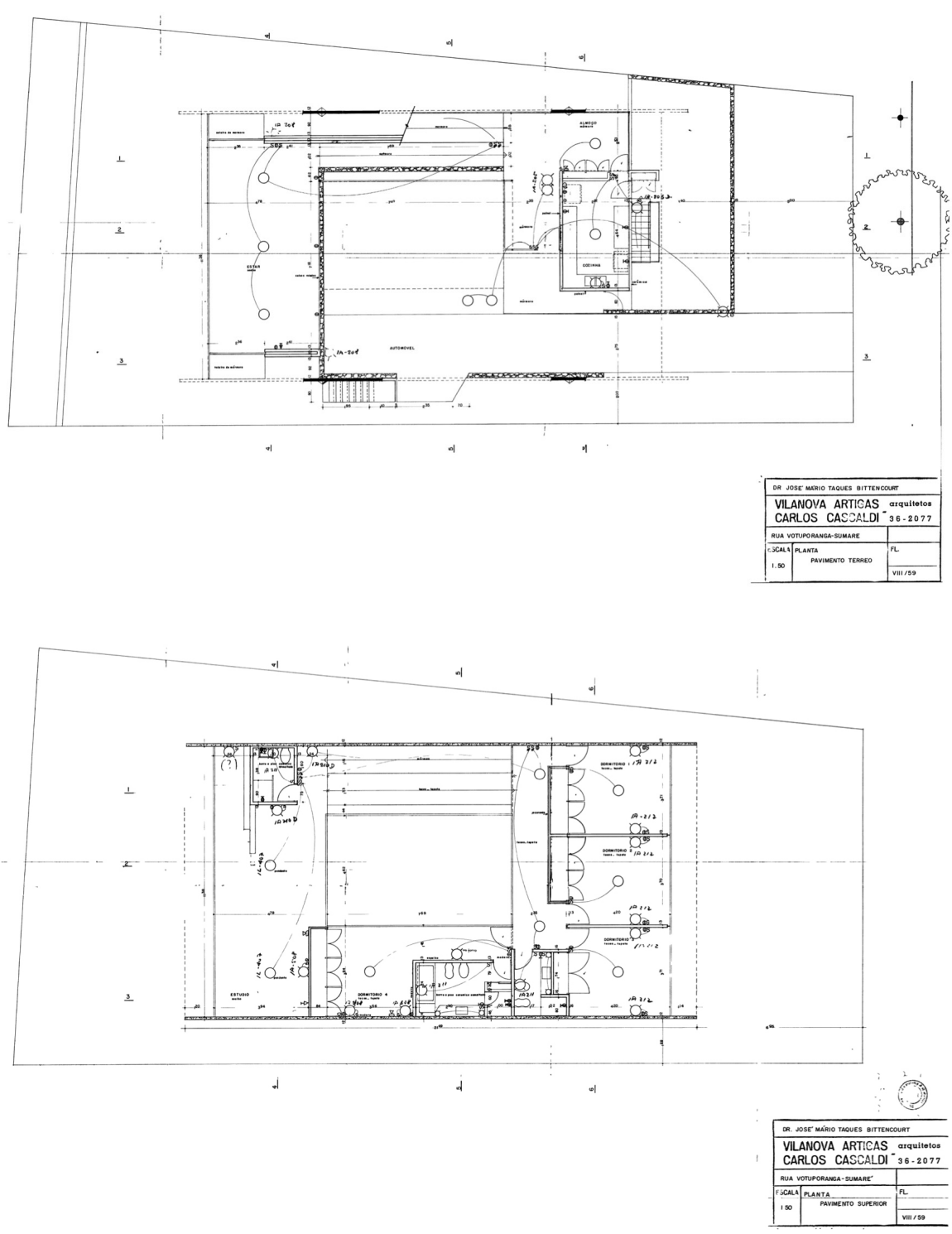

Figura 6 (topo): Planta baixa do pavimento térreo da segunda casa Mario Taques Bittencourt. Arq. Vilanova Artigas e Carlos Cascaldi, 1959, São Paulo. Fonte: Arquivo FAU/USP, (728-3 Jb).

Figura 7 (centro): Planta baixa do pavimento superior da segunda casa Mario Taques Bittencourt. Arq. Vilanova Artigas e Carlos Cascaldi, 1959, São Paulo. Fonte: Arquivo FAU/USP, (728-3 Jb).

Figura 8: Cortes da segunda casa Mario Taques Bittencourt. Arq. Vilanova Artigas e Carlos Cascaldi, 1959, São Paulo. Fonte: Arquivo FAU/USP, (728-3 Jb).

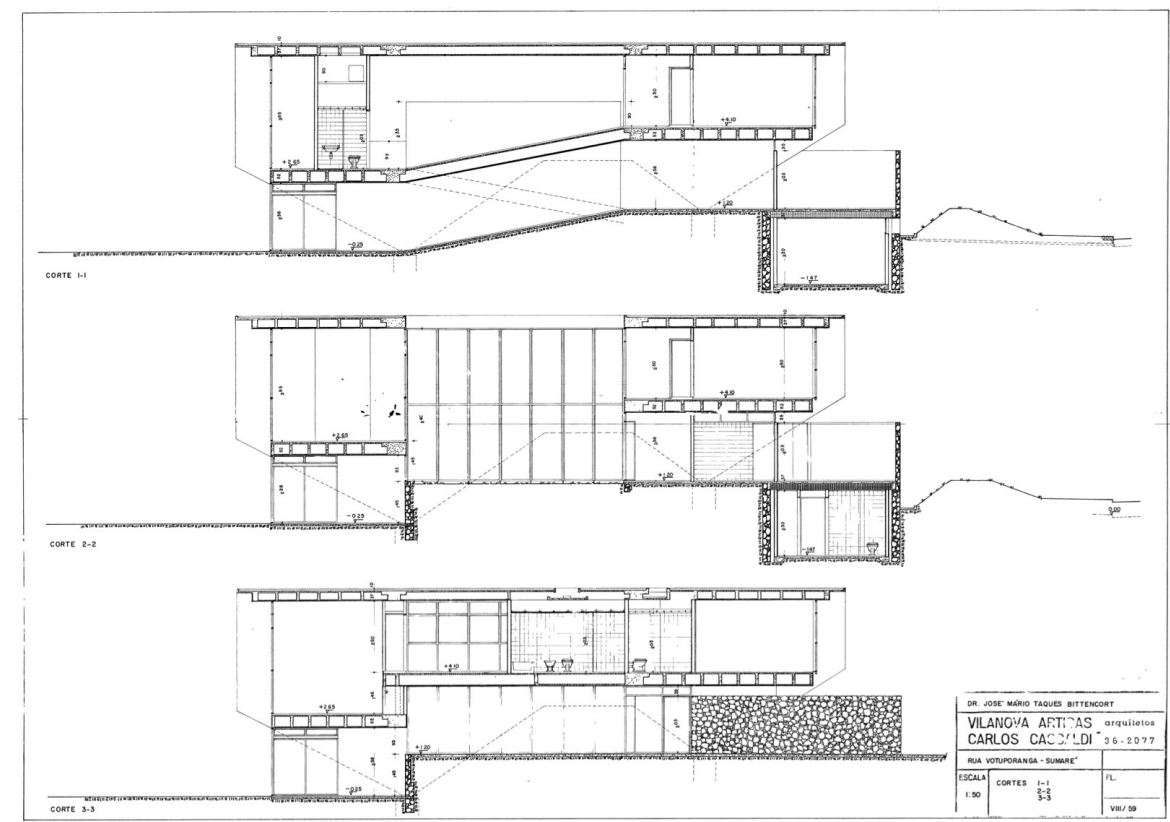




\section{O estudo não construído}

Quando se examina o desenvolvimento do projeto como um todo - incluindo o primeiro estudo -, fica ainda mais evidente, devido à reviravolta entre este primeiro e o segundo estudo, o radicalismo da proposta final. E se adverte certa hesitação quanto ao rumo definitivo do projeto. Esta hesitação se situa entre o prenúncio a partir da casa Olga Baeta e a clareza da casa construída em 1959 para o médico Taques Bittencourt e sua família. De fato, na casa Olga Baeta, o abandono de uma solução estrutural tradicional (lajes apoiadas em vigas e estas em pilares) já tinha sido anunciado, ainda que por diversos motivos não tenha sido de todo alcançado. Entre estes motivos está o fato de não ter sido possível a execução da escora (Figura 9) que, internamente, substituiria a empena presente nas fachadas.
Figura 9 (topo): Corte da casa Olga Baeta (1956). Na zona de pé-direito duplo pode-se identificar a escora em concreto armado não realizada no projeto construído. Fonte: Arquivo FAU/USP.

Figura 10: Vista aérea das três casas para a família Taques Bittencourt. A segunda foi substituída pelo estudo inicial não construído. Fonte: Laboratório de pesquisa Projeto e Memória (LPPM - UFPB), <lppm.com.br>.
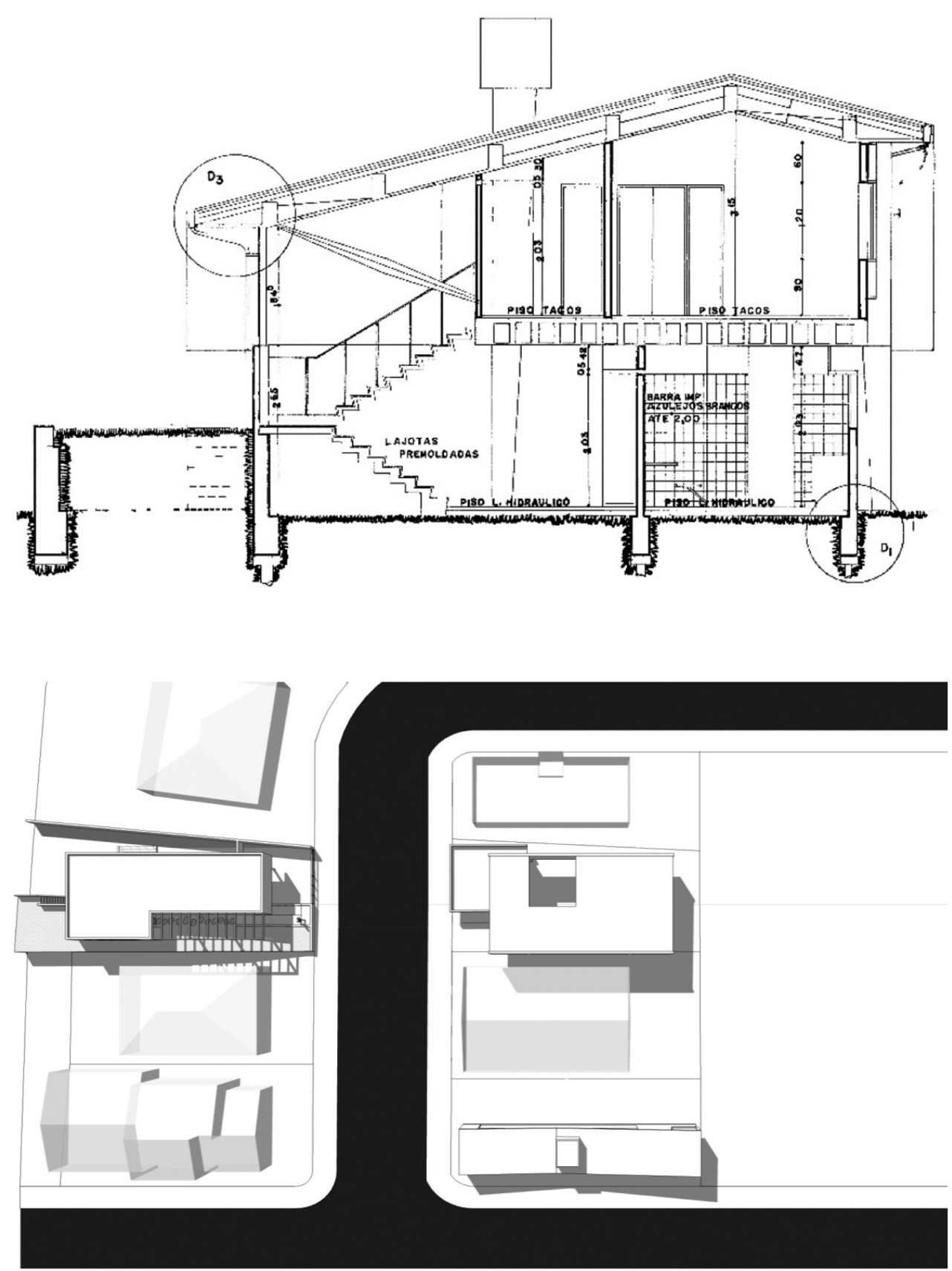

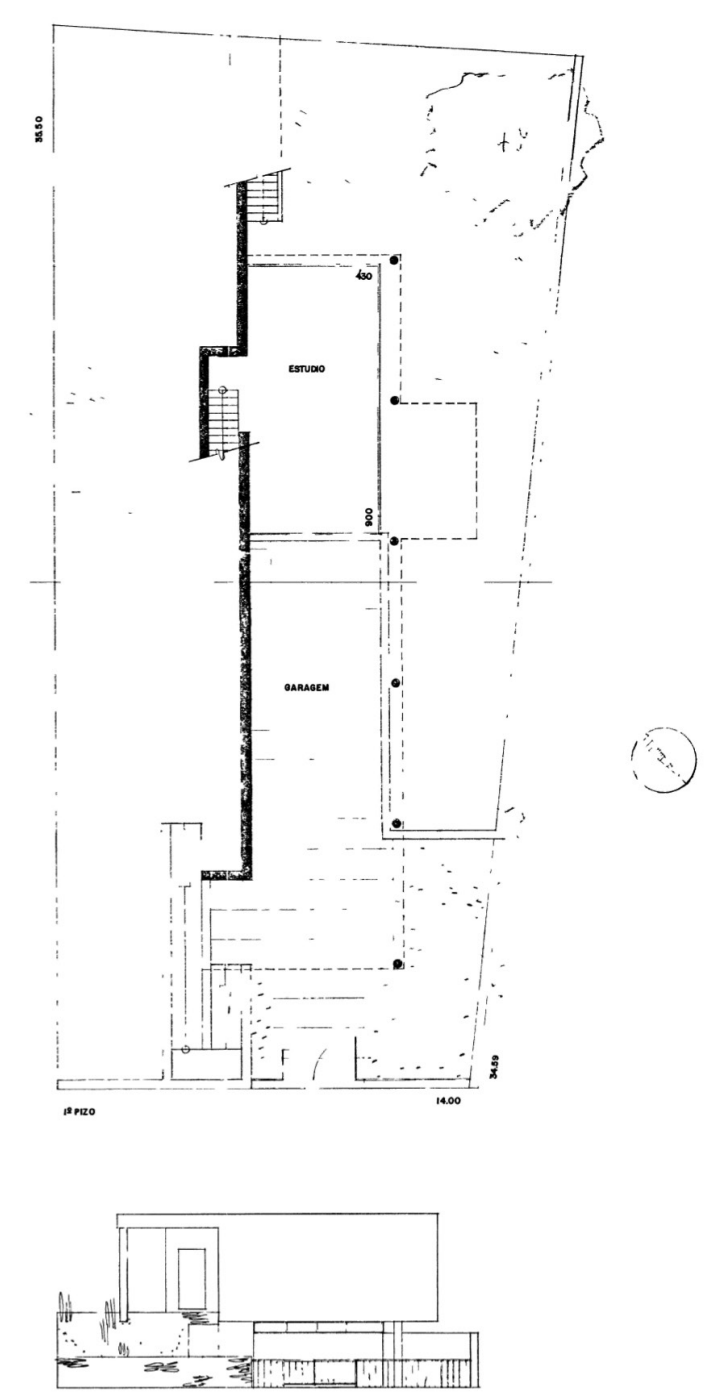

Figura 11: Planta do estudo inicial (não construído) da segunda casa Mario Taques Bittencourt. Arq. Vilanova Artigas e Carlos Cascaldi, 1959, São Paulo. Fonte: Arquivo FAU/USP, (728-3 Jb).

\section{Movimentação de terras, o acesso e a relação com a cidade}

No primeiro estudo (figuras 11, 12 e 13) chama a atenção a forte movimentação de terras que seria exigida caso viesse a ser construído, negligenciando o declive natural do terreno. O projeto dividiu em duas partes o lote por meio de um corte abrupto que exigiria uma quantidade significativa de aterro. Não se pode dizer ao certo o motivo desta decisão, mas por meio dela define-se a área de garagem e a imagem de volume sobre pilotis.

Parece também ser esta decisão que determina o acesso principal pela cota mais alta. Este acesso, que serve tanto a quem vem caminhando desde a rua, como da garagem, se dá por meio de dois lances de rampas e é emoldurado, no seu trecho final, por

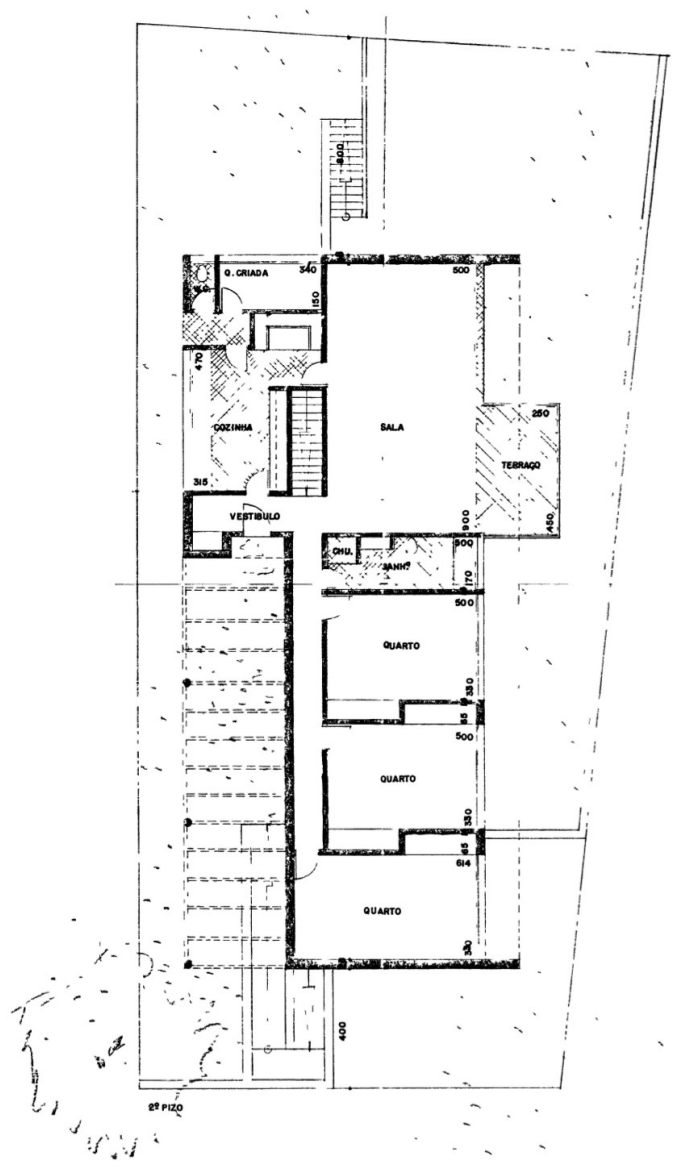

uma pérgula. Até aqui, ao menos duas diferenças fundamentais entre os dois projetos - o construído e o estudo inicial - se manifestam claramente: a forma de lidar com o terreno e a consequente relação que estabelece com a cidade. Ao contrário do identificado no estudo inicial, no projeto definitivo, Artigas se apropria da declividade natural do terreno (figura 8), o que por sua vez gerou dois outros aspectos importantes: (1) o acesso pelo mesmo nível da rua, tanto para quem chega caminhando como para quem chega de automóvel; (2) a organização do programa em níveis intermediários, acomodando-o à declividade já comentada. Esta solução já havia sido testada por Artigas em diversas ocasiões, notadamente oito anos antes, ali mesmo no bairro do Sumaré, em uma situação muito semelhante, a da casa construída para Oduvaldo Viana (Figura 14). Por que, então, não usa-la novamente? 

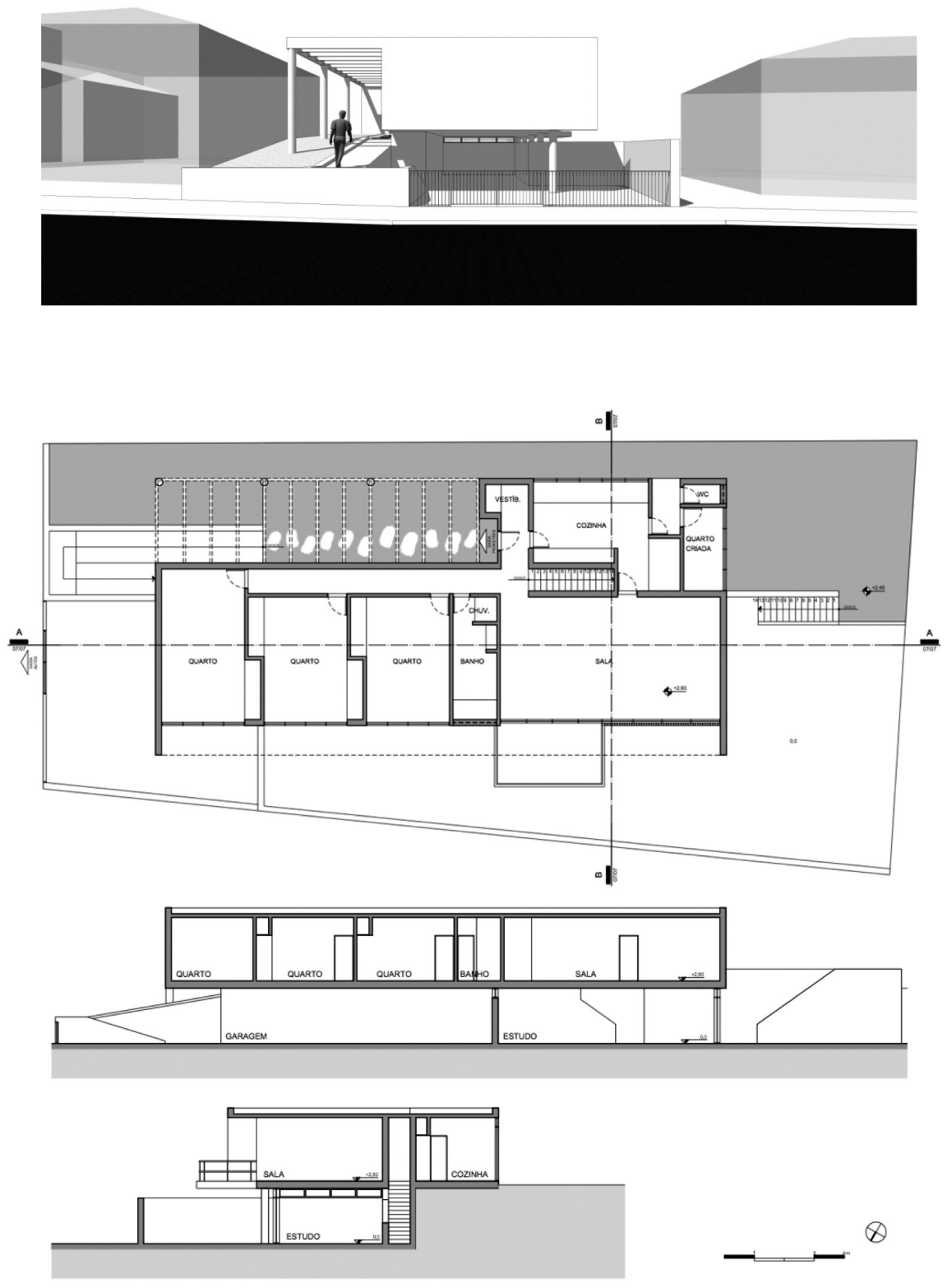

Figura 12 (topo): Perspectiva gerada a partir de um modelo digital do estudo não construído para a segunda casa da família Taques Bittencourt. Fonte: Laboratório de pesquisa Projeto e Memória (LPPM - UFPB), <lppm.com.br>.

Figura 13 (centro): Planta e cortes do estudo não construído para a segunda casa da família Taques Bittencourt. Fonte: Laboratório de pesquisa Projeto e Memória (LPPM - UFPB), <lppm.com.br>.

Figura 14: Corte casa Oduvaldo Viana, bairro do Sumaré, São Paulo. 1951. Arq. Vilanova Artigas Fonte: Acrópole $n^{\circ} 204$, 1955.

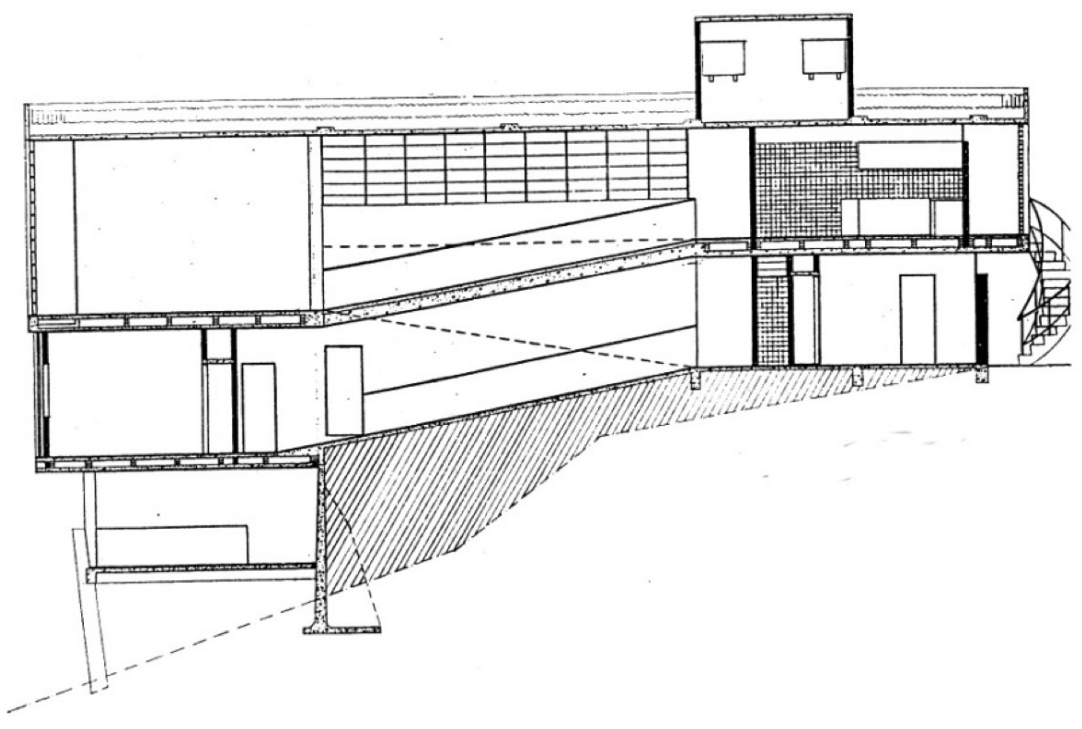


Figura 15: "Casca" da segunda casa Mario Taques Bittencourt. Arq. Vilanova Artigas e Carlos Cascaldi, 1959, São Paulo. Fonte: desenho elaborado pelo autor.

Figura 16: Perspectivas geradas a partir de um modelo digital do estudo não construído para a segunda casa da família Taques Bittencourt. Fonte: Laboratório de pesquisa Projeto e Memória (LPPM - UFPB), <lppm.com.br>

\section{Estrutura, forma e espaço}

A ausência de paredes sob a pérgula de acesso revela o conjunto de pilotis periféricos que se manifesta, ora na cota mais baixa, ora na cota mais alta. Ao que tudo indica, são doze pilares formando módulos de aproximadamente 4,0m. 0 sistema estrutural é claramente menos radical que a proposta construída e se alinha mais às soluções forjadas pela arquitetura moderna de matriz carioca do que àquelas que consagraram Artigas nos anos 1960. Essas diferenças repercutem diretamente em outros aspectos das duas versões do projeto. Enquanto a casa construída é percebida a partir de uma grande e única cobertura (figura 15) que parece dobra-se nas laterais de maior dimensão, até tocar de modo bastante original o solo, o primeiro estudo é compreendido por meio de volumes identificáveis, metade apoiados diretamente ao chão e a outra metade sobre pilotis (figura 16). Por que então não iniciar o projeto partindo da solução estrutural experimentada na casa Olga Baeta?

No projeto definitivo, a delimitação de um único plano como cobertura, cuja estrutura é perimetral e associada à declividade do terreno, permitiu a separação do programa em plantas intermediárias, interligadas por rampas, as quais em uma situação idealizada prolongam o plano da rua. Deste modo criou-se a possibilidade de dois percursos diferentes a partir do acesso principal. Tal como já tinha sido experimentado em diversos outros projetos, o escritório - a peça mais genérica do programa assumiu um papel de transição entre as zonas sociais e íntimas da casa. Um pátio descoberto é gerado em função das medidas exigidas pelas rampas e estrutura toda a circulação, propiciando relações visuais entre todos os pavimentos.
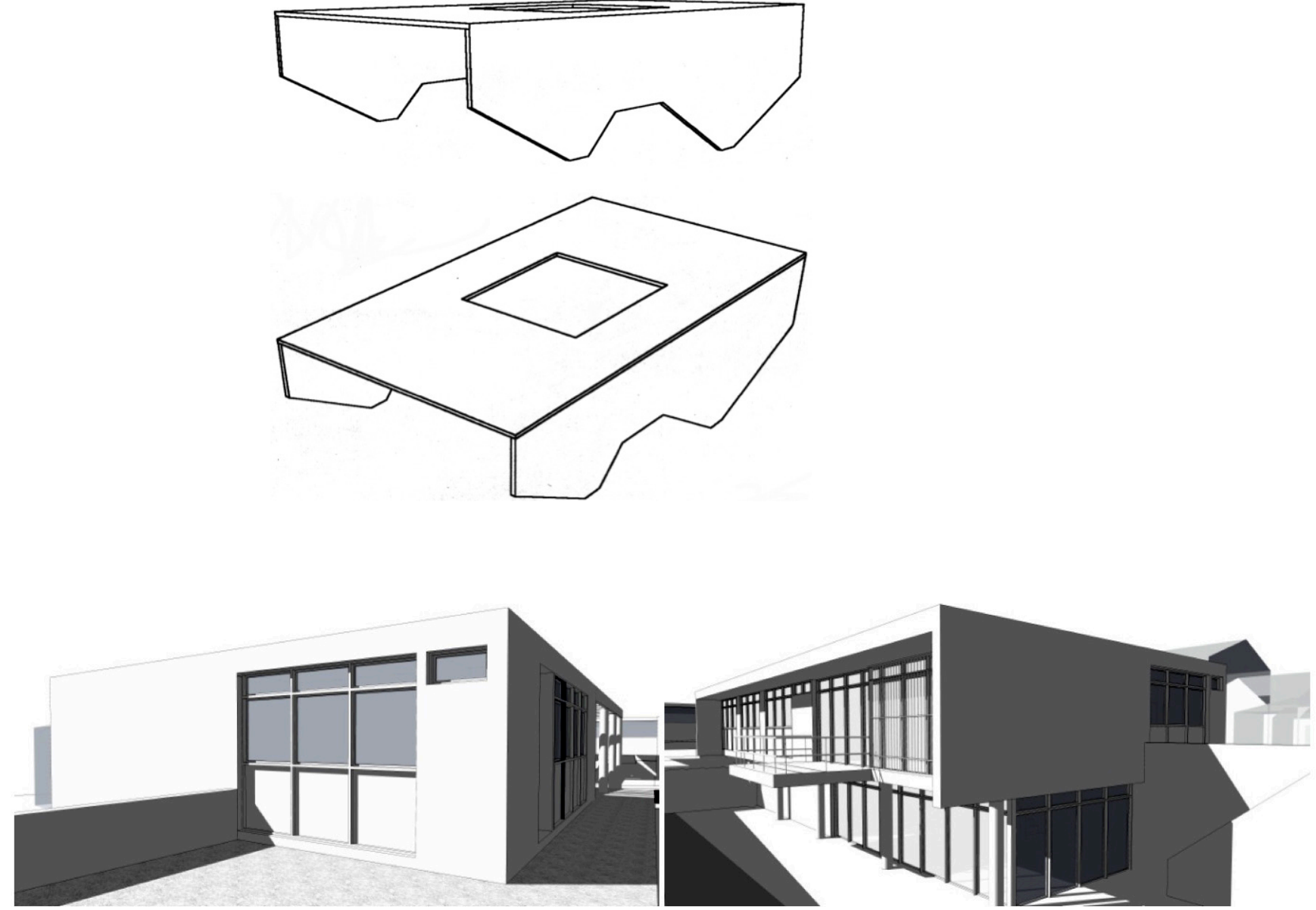


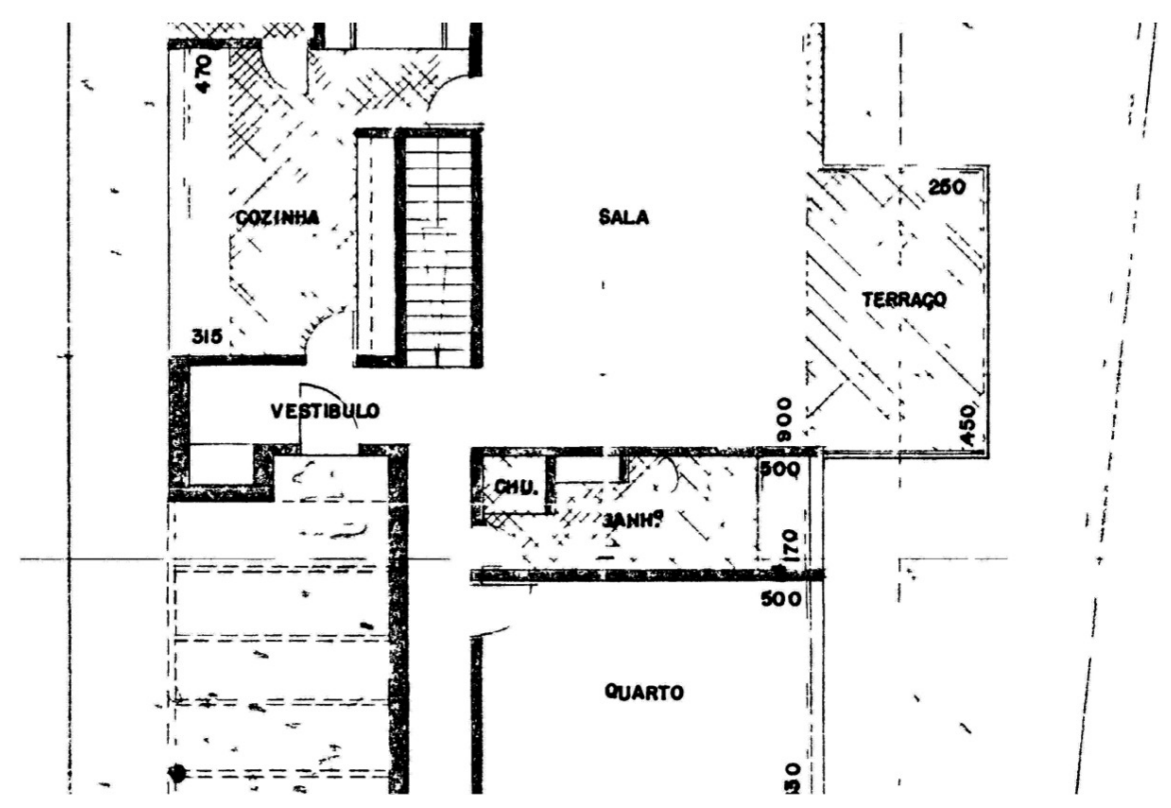

Figura 17: Vestíbulo e escada do estudo inicial (não construído) da segunda casa Mario Taques Bittencourt. Arq. Vilanova Artigas e Carlos Cascaldi, 1959, São Paulo. Fonte: Arquivo FAU/USP, (728-3 Jb).
No primeiro estudo Artigas opta por uma organização mais tradicional (figura 17). Ele dispõe todo o programa em uma mesma planta (a cota mais alta e também a de acesso), distribuindo por meio de um vestíbulo os diferentes setores claramente delimitados (íntimo, social e serviço). Desde este vestíbulo se pode também descer ao estúdio e acessar o jardim situado na mesma cota da garagem e do acesso ao terreno. Às rampas, que conectam a garagem ao pavimento principal, foi atribuída apenas a função de circulação vertical, ou seja, a de ligar duas cotas diferentes, enquanto na versão construída, as rampas são decisivas ao somarem função de circulação vertical e horizontal, permitindo que o usuário desloque-se horizontalmente no espaço entre o início e fim de cada trecho.

Por que Artigas define um arranjo tripartido e setorizado de modo tradicional, quando já tinha percebido as possibilidades espaciais ao associar rampas, cobertura única, plantas em níveis intermediários e o estúdio como peça transitória?

\section{Entre o estudo inicial e o projeto definitivo}

Inúmeras outras perguntas poderiam ser formuladas sobre as diferenças entre o primeiro estudo e o projeto definitivo da casa construída em 1959 para o médico e sua família, entretanto, muito provavelmente, nenhuma poderá ser respondida de modo satisfatório, sem basear-se apenas em especulações parciais a partir do constatado nos próprios projetos. Mesmo se Vilanova Artigas pudesse respondê-las, ainda assim as respostas seriam distantes das motivações que em 1959 o levaram a tal mudança de rumo, a tal reviravolta. Contudo, não se trata de porquês, o objetivo não é desvelar o que leva Artigas a movimentar-se drasticamente em outra direção, mas sim perceber quais aspectos caracterizam esta movimentação. A partir da comparação entre o estudo inicial e o projeto definitivo, pôde-se destacar ao menos três destes aspectos: uma solução estrutural caracterizada por apoios perimetrais, definindo uma única cobertura; o acesso pelo mesmo nível da rua e a organização do programa em níveis intermediários, acomodando-o à declividade natural do terreno; e um arranjo espacial que concentra nas rampas o papel de circulação vertical e horizontal e enquanto atribui ao estúdio o caráter transitório entre as zonas intimas e sociais da casa. Não são os únicos, certamente há outros, mas estes chamam a atenção pela indissociabilidade. Rampas, cobertura única, níveis intermediários e o estúdio, funcionam como um sistema único e associado, capaz de aclimatar-se a diferentes programas e escalas.

É muito provável que o caráter adaptável e em certo sentido generalizável, tenha sido o motivo pelo qual a solução testada na terceira casa para a família Taques Bittencourt tenha sido tão decisiva na formulação, a partir dos anos 1960, de uma das inúmeras correntes no quadro geral da arquitetura moderna brasileira. 


\section{Referências bibliográficas}

ACAYABA, Marlene Milan. Residências Paulistas 1947 1975. São Paulo: Projeto, s.d.

ACAYABA, Marlene. Brutalismo Caboclo e as residências paulistas, Projeto, n. 73, mar. 1985, pp. $46-48$.

ALFIERI, Bruno. "João Vilanova Artigas: ricerca brutalista". Revista Zodiac, n.6, 1960.

ANDREOLI, Elisabetta; et al. BRAZIL'S MODERN ARCHITECTURE. Londres: Phaidon, 2004, 240p.

ARTIGAS, Vilanova. "Revisão critica de Niemeyer", revista Acrópole, n.237, São Paulo, ano 20, jul. 1958.

ARTIGAS, Vilanova. "Uma falsa crise”, revista Acrópole, n.319, São Paulo, ano 27, jul. 1965.

ARTIGAS, Vilanova. A Função Social do Arquiteto. São Paulo: Fundação Vilanova Artigas/ Nobel, 1989. São Paulo: LECH, 1981.

BUZZAR, Miguel. João Batista Vilanova Artigas. Elementos para a compreensão de um caminho da arquitetura brasileira, 1938-1967. Editora Senad Unesp, 2014

COMAS, Carlos Eduardo Dias. "Moderna (1930 a 1960)". In: MONTEZUMA, Roberto. Arquitetura Brasil 500 anos. Recife: UFPE, 2002, p. 237.

COTRIM, Marcio. Construir a casa paulista: o discurso e a obra de Vilanova Artigas (1967-1985). Tese de doutorado, ETSAB-UPC, Barcelona, 2008.

Figura 18: Vista aérea das três casas para a família Taques Bittencourt. A segunda foi substituída pelo estudo inicial não construído. Fonte: Laboratório de pesquisa Projeto e Memória (LPPM - UFPB), <lppm.com.br>
GUERRA, Abílio; RIBEIRO, Alessandro Castroviejo. " Casas Portal Vitruvius.<http://www.vitruvius.com.br/arquitextos/arq074/arq074_01.asp>.

IRIGOYEN, Adriana. Wright e Artigas. Duas Viagens. São Paulo: Atelier Editorial, 2002 brasileiras do século XX". Arquitextos, n.074.01,
KAMITA, João Massao. Vilanova Artigas. São Paulo: Cosac Naify, 2000.

MEDRANO, Leandro; RECAMÁN, Luiz. Vilanova Artigas. Habitação e cidade na modernização brasileira. Campinas, Editora Unicamp, 2013.

PENTEADO, Fabio. "Vilanova Artigas, Construtor de Escolas". Revista Acrópole, n.337, 1970.

PENTEADO, Fabio. Fabio Penteado. Ensaios de Arquitetura. 1998, p.20.

ROSA, Artigas. Vilanova Artigas. São Paulo: editora Terceiro nome, 2015.

XAVIER, Alberto (org). Depoimento de uma geração: arquitetura moderna brasileira. São Paulo: Cosac \& Naify, 2002.

XAVIER, Alberto. Arquitetura Moderna paulistana. São Paulo: Pini, 1983, 245p.

XAVIER, Alberto; LEMOS, Carlos; CORONA, Eduardo. Arquitetura moderna paulistana. São Paulo: Pini, 1983. $251 \mathrm{p}$.

ZEIN, Ruth Verde. "A obra do arquiteto". Revista Projeto, suplemento especial: Tendências Atuais da Arquitetura Brasileira/ Vilanova Artigas 1915/1985. s/d, pp.33-45

ZEIN, Ruth Verde. A Arquitetura da Escola Paulista Brutalista 1953-1973. Porto Alegre, Tese de Doutorado, UFRS, 2005.

\section{Depoimentos}

Depoimento de Tito Lívio Mauro, atual proprietário da 3 a Casa Taques Bittencourt, ao autor em junho de 2005.

Depoimento de Doris Taques Bittencourt, proprietária da $1^{a}$ e $2^{a}$ casas construídas para a família Taques Bittencourt, ao autor em junho de 2005.

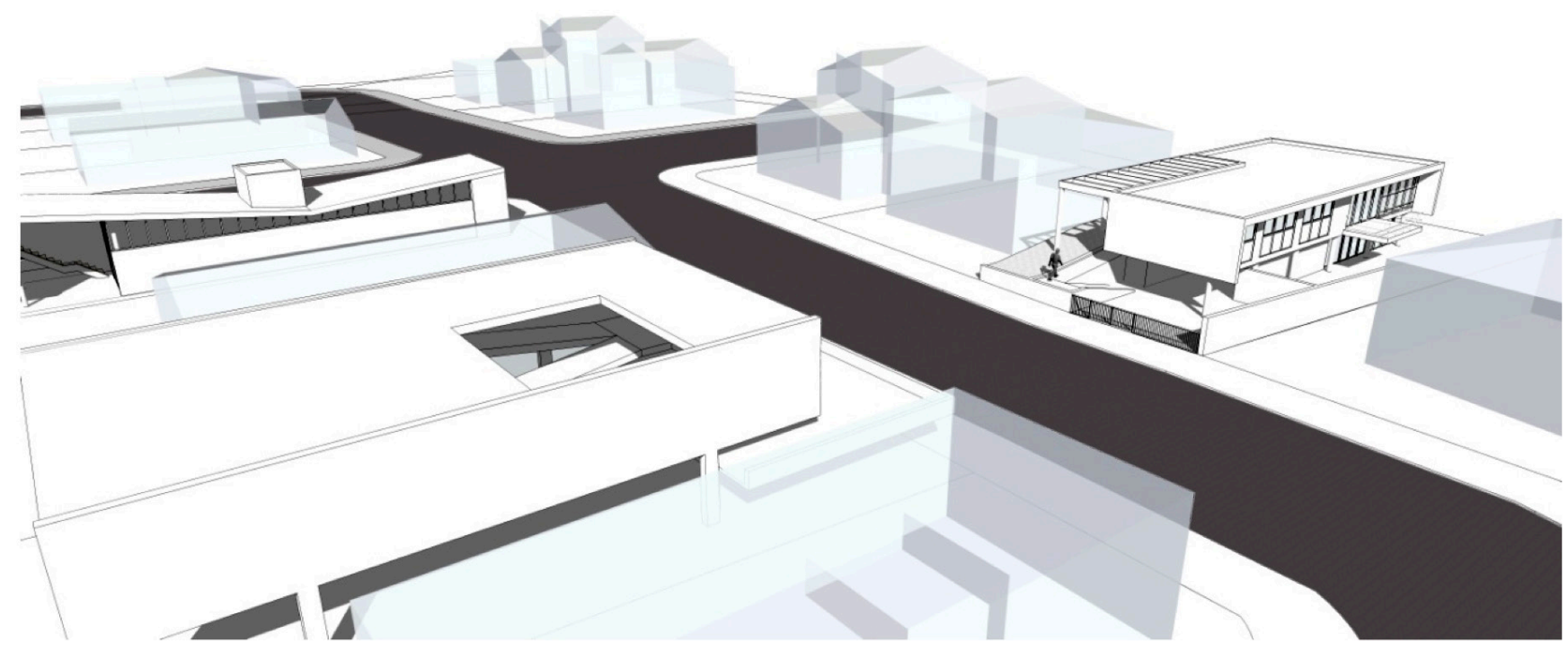

